\title{
Focal Ablation Therapy for Prostate Cancer: A Literature Review
}

\author{
Ruiqing Liu, MD ${ }^{a, d}$, Yaqiong Li, PhD ${ }^{b, d}$, Bing Mao, MD ${ }^{c, d}, \mathrm{Na} L i, \mathrm{PhD}^{d}$, Shaobo Duan, MD ${ }^{d}$, Zhiyang Chang, MS ${ }^{d}$, \\ Ye Zhang, MS ${ }^{d}$, Shuaiyang Wang, MS ${ }^{d}$, Lianzhong Zhang, MD ${ }^{d, e, ~ * ~}$
}

${ }^{a}$ Department of Interventional Therapy, Henan Provincial People's Hospital, Zhengzhou University People's Hospital, Henan University People's Hospital, Zhengzhou, Henan, China; ${ }^{b}$ Department of Pharmacy, Henan Provincial People's Hospital, Zhengzhou University People's Hospital, Henan University People's Hospital, Zhengzhou, Henan, China; ${ }^{c}$ Department of Public Department, Henan Provincial People's Hospital, Zhengzhou, Henan, China; ${ }^{d}$ Henan Engineering Technology Research Center of Ultrasonic Molecular Imaging and Nanotechnology, Zhengzhou, Henan, China; ${ }^{e}$ Department of Ultrasound, Henan Provincial People's Hospital, Zhengzhou University People's Hospital, Henan University People's Hospital, Zhengzhou, Henan, China

Received May 8, 2020; revision received June 17, 2020; accepted August 28, 2020

\begin{abstract}
The incidence and mortality of prostate cancer (PCa) are gradually increasing. Traditional treatments for PCa may result numerous side effects and complications that affect patients' quality of life. Furthermore, older patients frequently cannot tolerate conventional treatments, such as surgery, chemotherapy, and radiotherapy. Thus, minimally invasive and effective therapeutic approaches for PCa need to be developed for clinical practice. Focal ablation therapy, which uses high temperature to destroy tumors, holds promise as one such approach. It has been applied to PCa in several countries with gradual success and clinical practice This review briefly discusses the application of high-intensity focused ultrasound ablation (HIFU), cryoablation, laser ablation (LA), and radiofrequency and microwave ablation (RFA, MWA) for PCa, including the principles of treatment, clinical effects, and complications. The aim of this review is to provide a reliable reference for the application of focal ablation therapy to PCa.
\end{abstract}

Keywords: Prostate cancer; High-intensity focused ultrasound; Cryoablation; Laser ablation; Radiofrequency ablation; Microwave ablation

Advanced Ultrasound in Diagnosis and Therapy 2020;04:308-314

DOI: 10.37015/AUDT.2020.200045

\section{Introduction}

The morbidity and mortality of prostate cancer (PCa) are gradually increasing worldwide [1]. With the widespread application of digital rectal examination (DRE), prostate-specific antigen (PSA) test, and transrectal ultrasound (TRUS), PCa is increasingly diagnosed in the early stage. Some of these patients (15\%) receiving active surveillance (AS) developed advanced $\mathrm{PCa}$ [2]. Traditional treatments, such as surgery, external radiotherapy, and endocrine therapy, can result in numerous side effects $[3,4]$. Management concerns include a variety of serious challenges, including local recurrence, hormone resistance, and intolerance of operation at an advanced age.

Focal ablation therapy aims to provide the effective oncological benefit of active treatment options while reducing the risk of side effects through preserving noncancerous tissues. Focal ablation therapy, including high-intensity focused ultrasound (HIFU), cryoablation, laser ablation (LA), radiofrequency ablation (RFA), and microwave ablation (MWA), possesses advantages of being minimally invasive and requiring local anesthesia, shorter length of stay in hospital, and fast recovery [5-7]. It has been tested in various countries and applied to $\mathrm{PCa}$ as well as to other benign and malignant tumors, and proven to be safe and effective. In this review, we aimed

* Corresponding Author: Department of Ultrasound, Henan Provincial People's Hospital, Zhengzhou University People's Hospital, Henan University People's Hospital, No. 7, Weiwu Rd., Jinshui Dist., Zhengzhou, Henan, 450003, China.

e-mail: zlz8777@163.com

2576-2508/O AUDT $2020 \cdot$ http://www.AUDT.org

This is an open-access article distributed under the terms of the Creative Commons Attribution 4.0 International license, which permits unrestricted use, distribution and reproduction in any medium provided that the original work is properly attributed. 
to present what is known about the application of focal ablation technologies for $\mathrm{PCa}$ and provide a reliable reference for future clinical application.

\section{HIFU}

\section{Principle}

HIFU is a noninvasive therapeutic technique, producing ultrasound waves generated by a spherical transducer. The ultrasonic energy is focused on a fixed point, and the temperature at the target point reaches 80 $100{ }^{\circ} \mathrm{C}$, resulting in tissue destruction through coagulative necrosis, while preserving adjacent tissues. The process is combined with cavitation, when microbubbles may form in the tissue and implode, causing mechanical damage by disruption of the cell membranes. It is precise for ablating prostate tissues with a sharply demarcated transition between the coagulated zone and the surrounding gland. The coagulated tissue can be gradually absorbed or scarred. The European Association of Urology guideline has recommended HIFU as an alternative therapy for the treatment of $\mathrm{PCa}[8]$.

\section{Clinical application}

The transrectal HIFU was first reported in the treatment of benign prostatic hyperplasia (BPH) in the 1980s [9]. The application of HIFU in localized PCa was officially reported in 1995 [10]. At present, HIFU can be used as a first-line treatment option for cases with low-to-medium-risk PCa who cannot tolerate traditional treatment [11], and it can also be used as a palliative treatment strategy for patients with advanced drugresistance. Due to the limitation of focal length, the volume of the prostate is generally below $40 \mathrm{ml}$ [12]. Transurethral resection of the prostate (TURP) can be performed before HIFU to reduce the size of the prostate and remove large calcified masses with diameter more than $1 \mathrm{~cm}$.

At present, biopsy is performed after HIFU to evaluate clinical effects. The results of a multi-center trial indicated that the negative rate of biopsy is 55$100 \%$ after HIFU treatment. The larger the prostate, the higher the positive biopsy rate for $\mathrm{PCa}$ and the higher the Gleason score [13-15]. The 5-year disease-free survival (DFS) rate of low- and middle-risk PCa patients after HIFU treatment was reported as high as $77 \%$ [16]. The combined PSA values with prostate biopsy are used to monitor recurrence after HIFU. PSA is an androgen-regulated serine protease produced by both prostate epithelial cells and $\mathrm{PCa}$, as well as being the most common serum marker for PCa. Previous research demonstrated that PSA can reach the lowest level (0.4 ng/ $\mathrm{ml}$ ) after treatment of $\mathrm{PCa}$ with HIFU [17]]. It has also been reported that a PSA level of $0.43 \mathrm{ng} / \mathrm{ml}$ is critical to predict recurrence after treating PCa with HIFU [18]. In 2017, a number of scholars compared functional and oncologic outcomes of HIFU hemiablation of the prostate with robot-assisted laparoscopic prostatectomy (RALP) in the treatment of unilateral PCa, and found that HIFU hemiablation was comparable to RALP in terms of controlling localized unilateral $\mathrm{PCa}$, with no significant differences in the need for salvage therapies [19].

In recent years, magnetic resonance imaging (MRI)guided HIFU treatment has gradually attracted attention. In 2017, Tay et al. and Ghai et al. reported the utilization of MRI-guided HIFU in the treatment of PCa with lowrisk and small lesions in Europe, and highlighted its safety and effectiveness in short-term follow-up [20, 21].

\section{Complications}

Common complications after HIFU include transient urine retention, sexual dysfunction, urinary incontinence, rectal burns, urethral fistula, and urethral stricture.

Transient urine retention is generally caused by temporary swelling of the prostate after HIFU, with an incidence of $6-32 \%$. Patients only rarely require longterm indwelling of the urinary catheter or bladder fistula [13-15].

The rate of erectile dysfunction is $24-77 \%$ after the HIFU. However, with the monitoring of neurovascular bundles during the treatment, this complication has been improved [20,21]. The causes of urinary incontinence include sphincter damage, genital nerve damage, and urethral droop, with an earlier reported incidence of $6-32 \%$. In recent years, with the advance of technologies, the incidence rate of urinary incontinence has gradually decreased to only $1-5 \%$ of patients needing intervention [13-15]. It has been pointed out that implementation of TURP before HIFU can reduce the incidence of stress urinary incontinence, urethral stricture, and bladder outlet obstruction [22]. The most severe complications are rectal burns and urethral fistula, and the use of rectal cooling devices reduces these complications [23]. Delayed complications of HFIU include primarily urethral stricture (2-17\%) [12-15].

\section{Cryoablation}

\section{Principle}

Cryoablation uses low-temperature freezing and rewarming of thawing to destroy tissues, resulting in irreversible damage to cells in target tissues. When the temperature is lower than zero, crystals appear in the extracellular fluid, high osmotic pressure forms between the inside and outside of cells, and water transfers from the inside to the outside of the cell, 
leading to cell dehydration and changes in $\mathrm{pH}$ value. The fluid is transferred into the cells, causing the cells to burst instantaneously, and at the same time, the vascular dilatation around the tissue leads to increased permeability of the vascular wall, damage to the endothelium, and microthrombi formation $[24,25]$.

\section{Clinical application}

Application of cryoablation to the treatment of BPH was first reported in 1966 [26], and use of transperineal cryoablation for PCa was reported in 1972 [27]. Since this method did not fully inactivate tumors $[28,29]$, and a number of complications were observed, so the cryoablation was not widely used in treating in prostate disease. However, this situation has improved as transrectal ultrasound and MRI monitoring the cryoablation process [30].

Cryoablation has gradually been applied more often to prostate diseases with the utilization of Foley's urethral protection of the urethra [31], rectal perfusion of saline [7], and temperature sensors placed on external anal sphincter and neurovascular bundles [32]. The American Urological Association detailed the application of cryoablation in local PCa in 2008 [25]. Cryoablation is generally used for low-risk (T1c-T2a; Gleason score, 6; PSA $<10 \mathrm{ng}-/ \mathrm{mL}$ ) and moderate-risk (Gleason score, 7; PSA, $10-20 \mathrm{ng} / \mathrm{mL}$ ) groups of patients with PCa. However, patients with lesions near the neurovascular bundle, severe lower urinary tract symptoms, or a prostate volume more than $50 \mathrm{ml}$ are not eligible for cryotherapy. Hormonal therapy can be used to reduce the size of the prostate to achieve indications [33].

There is still no consensus on how to determine tumor recurrence after cryoablation. Due to the PSA released by the necrosis cells after ablation, PSA generally reaches the nadir within 3 months after treatment [33]. In addition, because prostate tissue around the urethra still exists, PSA can still be detected in the serum. Generally, a biopsy is undertaken at 6 and 12 months after cryoablation to detect tumor cells. The literature has reported a positive rate of $7.7-23 \%$ [31-35].

Randomized controlled trials (RCTs) have confirmed that long-term survival outcomes are similar for cryoablation and radiotherapy for localized PCa [36]. In 2008, Jones et al. reported follow-up data for cryotherapy for $\mathrm{PCa}$, and pointed out that the survival rate was related to tumor stage [37]. In 2015, Guo et al. studied the use of cryoablation to treat stage T3 PCa patients, and the 5-year overall survival (OS) was $85.3 \%$ [38].

\section{Complications}

Common complications of cryoablation for $\mathrm{PCa}$ include sexual dysfunction, urinary incontinence, urinary retention, urethral stricture, urethral fistula [39], and penile numbness [33]. It has been reported that cryoablation has a more significant influence on sexual function than external radiotherapy; thus, patients who aim to retain sexual function may not be eligible for cryoablation [40]. Urinary incontinence may gradually recover after ablation, and swelling in the penis or scrotum, hydronephrosis, and small bowel obstruction were rarely reported [41]. However, with continuous improvement of medical technology and application of protective measures, complications may be remarkably alleviated.

\section{LA}

\section{Principle}

LA is the transmission of light into tissues through a $21 \mathrm{G}$ Chiba needle quartz fiber with a diameter of 300$600 \mathrm{um}$. The high temperature in tissues occurs after absorbance of light, and irreversible damage may be observed in tumor cells after exposure to temperatures above $60{ }^{\circ} \mathrm{C}$ [42]. The penetration depths in tissues differ according to the wavelength of laser. The infrared penetration is ideal. Diode laser with a wavelength of 800-980 $\mathrm{nm}$ and yttrium aluminum garnet (Nd: YAG) laser with a wavelength of 1064 um have a penetration depth of about $10 \mathrm{~cm}$.

The earliest LA was called "bare fiber" [43]. Several efforts were made to elevate the ablation volume by increasing the power while avoiding carbonization of the surrounding tissue, including sapphire tip fiber, fiber end plus laser emitter, and cold cycle [44]. These measures reduce the impact of carbonization on the penetration of light, as well as expanding the scope of ablation [45]. The volume of LA is not only related to the light source and the medium, but also can be affected by the characteristics of tissues, especially tissue perfusion. The high tissue perfusion or surrounding large blood vessels affect the laser heating as a "radiator", because hemoglobin can absorb light, and heat is taken away [46].

\section{Clinical application}

Salon et al. first used laser as a surgical tool [47]. In the 1980s, LA was utilized for the treatment of brain and prostate tumors $[48,49]$.

Lindner et al. conducted LA on two batches of patients with PCa. There were 12 cases of $\mathrm{PCa}$ in the first batch, and after 6 months of LA, the biopsy showed no tumor in $67 \%$ of the target area and no tumor in $50 \%$ of the whole glands, and there were no significant complications [50]. In the other batch, the patients underwent $\mathrm{PCa}$ resection 1 week after ablation, and the postoperative pathology revealed that the ablation lesions 
were even coagulation necrosis, with clear borders and surrounding bleeding rings [51].

In 2013, Aytekin et al. used MRI-guided transperineal biopsy for patients with low-risk PCa, and after half a year, 78\% (7/9) of tumor cells were faded in the ablation area [52]. The MRI-guided LA for moderate-risk PCa was found safe and feasible in a phase I clinical trial, which was conducted by the University of California, Los Angeles, in 2015 [53]. In the subsequent phase II clinical trial, LA was used to treat low-risk PCa patients (T1c-T2a), and the three-month biopsy negative rate was 96\% [54]. With development and advancement of multimodal medical image, the ablation will become more accurate. The fusion images of MRI and ultrasound were employed to guide transrectal LA for patients with moderate-risk PCa. After half a year, the results of biopsy unveiled that $30 \%$ of patients were tumor-free, local tumors were found in $30 \%$ of patients with Gleason score 6 , and $40 \%$ had sustained moderate-risk PCa [55].

At present, LA is extensively utilized for the treatment of low- or moderate-risk PCa (PSA $<15 \mathrm{ng} / \mathrm{mL}$; Gleason score, 6-7; clinical-stage, T1c-T2a). Because the maximum ablation area of a single laser is about $2-3 \mathrm{~cm}$ in diameter, it may be a risk for LA in some large tumors or tumors adjacent to the critical organs, such as vascular nerve bundles, urethral sphincter, and rectal wall.

\section{Complications}

At present, the LA in the clinical treatment of $\mathrm{PCa}$ is mainly in phase I-II clinical trials [52-54], indicating that it is safe and feasible, while few studies have yet reported complications. The most common complications include hematuria $(15 \%)$, perineal ecchymosis or abrasion $(11 \%)$, glans paresthesia (11.1\%), acute urinary incontinence (4\%), and sexual dysfunction. Among them, hematuria does not need special treatment, and it will gradually disappear after a few days. Sexual dysfunction generally reaches the lowest level during 1-3 months after LA, and it will gradually return to normal after 1 year [52].

\section{RFA and MWA}

\section{Principle}

RFA and MWA are currently dominant modalities to treat unresectable liver tumors. The ions and molecules in the tissue oscillate under the current and electromagnetic waves, respectively, and irreversible damage to cells happens under high temperature. The difference is that carbonization occurs when the temperature is extremely high during RFA, which hinders the propagation of RF current and limits the range of ablation. MWA is not affected by current, tissue drying, and carbonization, and a relatively broad range of damage occurs in a short period of time

\section{Clinical application}

When these two ablation technologies were used for $\mathrm{PCa}$ via transurethral or rectal puncture [56-58], and the results indicated that this method caused damage to the urethra or rectum. Thus, perineal puncture was recently used in the ablation of PCa. Previous research pointed out that the RFA can be used in treating PCa through TRUSguided perineal puncture. At 1 week after ablation, the prostates were obtained by the surgeon, and the pathologist confirmed that all lesions were inactivated. The size of lesions was $2 \times 2 \times 2 \mathrm{~cm}$. MRI predicted that the lesions were consistent with the pathology $[59,60]$.

In China, Wu et al. [61] and $\mathrm{Hu}$ et al. [62] demonstrated the application of RFA to PCa through perineal puncture under CT or ultrasound guidance in 2002, proving that this method does not cause damage to the urethra, does shorten the length of hospital stay, and is safe and effective as well. Additionally, it was uncovered that the distance from the RF electrode to the urethral sphincter near the apex of the prostate should be more than $1 \mathrm{~cm}$ to avoid urinary incontinence caused by urethral sphincter damage $[61,62]$.

A pilot study that evaluated the recurrence after RFA for PCa in 2005 showed that in $90 \%$ of the patients PSA decreased more $50 \%$; in $72 \%$ of the patients PSA reduced by more than $70 \%$; and in $46 \%$ of the patients PSA decreased by more than $80 \%$. Besides, the PSA doubling time was remarkably shorter than before the ablation [63]. In China, RFA was used for PCa through perineal puncture under CT or TRUS guidance, highlighting the feasibility of this technique accompanied by excellent clinical outcomes [64-66].

\section{Complications}

The most common complications of RFA are transient gross hematuria (4.5-19\%) and fever. There are also bladder spasms $(9 \%)$, dysuria $(9 \%)$, urinary tract irritation (13.6\%), and local hematoma (4.5\%), and other complications. The above-mentioned conditions returned to normal after RFA within a short period of time $[62,63,65,66]$. Xu et al. reported a case of rectal bladder fistula after ablation, and the urinary catheter was left for 1 week to observe the hematuria and prevent acute urinary retention.

\section{Conclusions}

Each focal ablation technology possesses advantages for treating PCa. Among them, the use of HIFU and cryoablation is relatively mature in different countries. An advantage of HIFU is being non-invasive while cryoablation is minimally noninvasive. However, in order to use HIFU and cryoablation technologies, the diameter 
of the tumor must be less than $4 \mathrm{~cm}$ and the volume of the prostate must be less than $40 \mathrm{mml}$. In addition, these methods are time-consuming (1-3 h). The diameter of the cryoablation probe is relatively large. During the ablation process, the urethra needs to be heated to prevent urethral damage and the cryoablation probe needs to be more than $1 \mathrm{~cm}$ away from the urethra to prevent urethral damage. The operation time is relatively short and can be performed with local anesthesia in outpatient clinics. However, there is currently no right way to monitor the precise range of ablation. In summary, focal ablation therapy should be individualized according to the location, size, and the number of tumors. Recently, Liu et al promise that the appropriate ablation technology can be selected for PCa patients according the shape and volume of ablated lesions through animal experiment results [67].

Focal ablation therapy is currently applied to localized $\mathrm{PCa}(\mathrm{PSA}<15 \mathrm{ng} / \mathrm{mL}$; T2a; Gleason score, $3+3$ or 3 +4) $[11,68]$. The concept of "Index Lesion" provides a theoretical basis for the focal ablation therapy of PCa. "Index Lesion" refers to the main lesions in $\mathrm{PCa}$ causing disease development, with a volume greater than $0.5 \mathrm{ml}$ or the Gleason score greater than $6[69,70]$. Hence, a number of scholars have demonstrated that ablation for index lesion will degrade other tumors. Multi-parametric MRI (mp-MRI) can show 92\% of the index lesions [71]. Recently, the fusion image of mp-MRI and TRUS was used to guide the ablation of PCa [72], combining the advantages of these two medical imaging technologies. The lesions displayed in the MRI and the process of puncture and ablation can be dynamically observed under TRUS.

Focal ablation offers a promising outlook for the future in the treatment of $\mathrm{PCa}$, with the goal of effectively achieving cancer control while minimizing morbidity. Additionally, it is critically important that good prospective randominzed clinical trials for each ablation technology be performed to assess the advantage of each treatment modality and to determine long-term efficacy.

\section{Acknowledgement}

This work was supported by the national key research and development program of China (Grant No. 2018YFC0114606). We wish to appreciate Ms. Jennifer Wilson from Thomas Jefferson University for revising and editing our manuscript.

\section{Conflict of Interest}

The authors declare that there is no conflict of interest.

\section{References}

[1] Chen W, Zheng R, Baade PD, Zhang S, Zeng H, Bray F, et al. Cancer statistics in China, 2015. CA Cancer J Clin 2016; 66: 115-132.

[2] Ratcliff CG, Cohen L, Pettaway CA, Parker PA. Treatment regret and quality of life following radical prostatectomy. Support Care Cancer 2013; $21: 3337-3343$.

[3] Sanda MG, Dunn RL, Michalski J, Sandler HM, Northouse L, Hembroff L, et al. Quality of life and satisfaction with outcome among prostate-cancer survivors. N Engl J Med 2008; 358: 12501261.

[4] Hoffman RM, Lo M, Clark JA, Albertsen PC, Barry MJ, Goodman $\mathrm{M}$, et al. Treatment decision regret among long-term survivors of localized prostate cancer: results from the prostate cancer outcomes study. J Clin Oncol 2017; 35: 2306-2314.

[5] Sanchez-Salas R, de la Rosette J, Polascik TJ, Carneiro A, Sivaraman A, Cathelineau X, et al. Focal therapy for prostate cancer: a more vehement view of the approach could translate into real benefits for our patients. Eur Urol 2018; 74: 537-539.

[6] Marshall S, Taneja S. Focal therapy for prostate cancer: The current status. Prostate Int 2015; 3: 35-41.

[7] Bozzini G, Colin P, Nevoux P, Villers A, Mordon S, Betrouni N. Focal therapy of prostate cancer: energies and procedures. Urol Oncol 2013; 31: 155-167.

[8] Kennedy JE. High-intensity focused ultrasound in the treatment of solid tumours. Nat Rev Cancer 2005; 5: 321-327.

[9] Bihrle R, Foster RS, Sanghvi NT, Donohue JP, Hood PJ. High intensity focused ultrasound for the treatment of benign prostatic hyperplasia: early United States clinical experience. J Urol 1994; 151: 1271-1275.

[10] Madersbacher S, Pedevilla M, Vingers L, Susani M, Marberger M. Effect of high-intensity focused ultrasound on human prostate cancer in vivo. Cancer Res 1995; 55: 3346-3351.

[11] Donaldson IA, Alonzi R, Barratt D, Barret E, Berge V, Bott S, et al. Focal therapy: patients, interventions, and outcomes--a report from a consensus meeting. Eur Urol 2015; 67: 771-777.

[12] Acher PL, Hodgson DJ, Murphy DG, Cahill DJ. High-intensity focused ultrasound for treating prostate cancer. BJU Int 2007; 99: 2832.

[13] Thuroff S, Chaussy C, Vallancien G, Wieland W, Kiel HJ, Le Duc A, et al. High-intensity focused ultrasound and localized prostate cancer: efficacy results from the European multicentric study. J Endourol 2003; 17: 673-677.

[14] Gelet A, Chapelon JY, Bouvier R, Rouviere O, Lasne Y, Lyonnet $\mathrm{D}$, et al. Transrectal high-intensity focused ultrasound: minimally invasive therapy of localized prostate cancer. J Endourol 2000; 14: 519-528.

[15] Uchida T, Sanghvi NT, Gardner TA, Koch MO, Ishii D, Minei S, et al. Transrectal high-intensity focused ultrasound for treatment of patients with stage $\mathrm{T} 1 \mathrm{~b}-2 \mathrm{n} 0 \mathrm{~m} 0$ localized prostate cancer: a preliminary report. Urology 2002; 59: 394-398; discussion 398-399.

[16] Blana A, Murat FJ, Walter B, Thuroff S, Wieland WF, Chaussy C, et al. First analysis of the long-term results with transrectal HIFU in patients with localised prostate cancer. Eur Urol 2008; 53: 1194 1201.

[17] Ahmed HU, Freeman A, Kirkham A, Sahu M, Scott R, Allen C, et al. Focal therapy for localized prostate cancer: a phase I/II trial. J Urol. 2011; 185: 1246-1254.

[18] Chen PY, Chiang PH, Liu YY, Chuang YC, Cheng YT. Primary whole-gland ablation for localized prostate cancer with high-intensity focused ultrasound: The important predictors of biochemical recurrence. Int J Urol 2018; 25: 615-620.

[19] Gill IS, Azzouzi AR, Emberton M, Coleman JA, Coeytaux E, Scherz A, et al. Randomized trial of partial gland ablation with vascular targeted phototherapy versus active surveillance for low risk prostate 
cancer: Extended followup and analyses of effectiveness. $J$ Urol 2018; 200: 786-793.

[20] Tay KJ, Cheng CWS, Lau WKO, Khoo J, Thng CH, Kwek JW. Focal therapy for prostate cancer with in-bore mr-guided focused ultrasound: two-year follow-up of a phase I trial-complications and functional outcomes. Radiology 2017; 285: 620-628.

[21] Ghai S, Perlis N, Lindner U, Hlasny E, Haider MA, Finelli A, et al. Magnetic resonance guided focused high frequency ultrasound ablation for focal therapy in prostate cancer - phase 1 trial. Eur Radiol 2018; 28: 4281-4287.

[22] Chaussy C, Thuroff S. The status of high-intensity focused ultrasound in the treatment of localized prostate cancer and the impact of a combined resection. Curr Urol Rep 2003; 4: 248-252.

[23] Gelet A, Chapelon JY, Bouvier R, Pangaud C, Lasne Y. Local control of prostate cancer by transrectal high intensity focused ultrasound therapy: preliminary results. $J$ Urol 1999; 161: 156-162.

[24] Han KR, Belldegrun AS. Third-generation cryosurgery for primary and recurrent prostate cancer. BJU Int 2004; 93: 14-18.

[25] Babaian RJ, Donnelly B, Bahn D, Baust JG, Dineen M, Ellis D, et al. Best practice statement on cryosurgery for the treatment of localized prostate cancer. J Urol 2008; 180: 1993-2004.

[26] Soanes WA, Gonder MJ, Shulman S. Apparatus and technique for cryosurgery of the prostate. $J$ Urol 1966; 96: 508-511.

[27] Reuter HJ. Endoscopic cryosurgery of prostate and bladder tumors. $J$ Urol 1972; 107: 389-393.

[28] Flocks RH, Nelson CM, Boatman DL. Perineal cryosurgery for prostatic carcinoma. J Urol 1972; 108: 933-935.

[29] Porter MP, Ahaghotu CA, Loening SA, See WA. Disease-free and overall survival after cryosurgical monotherapy for clinical stages B and C carcinoma of the prostate: a 20-year followup. J Urol 1997; 158: 1466-1469.

[30] Woodrum DA, Kawashima A, Gorny KR, Mynderse LA. Prostate cancer: state of the art imaging and focal treatment. Clin Radiol 2017; 72: 665-679.

[31] Onik GM, Cohen JK, Reyes GD, Rubinsky B, Chang Z, Baust J. Transrectal ultrasound-guided percutaneous radical cryosurgical ablation of the prostate. Cancer 1993; 72: 1291-1299.

[32] Jacome-Pita F, Sanchez-Salas R, Barret E, Amaruch N, GonzalezEnguita $\mathrm{C}$, Cathelineau X. Focal therapy in prostate cancer: the current situation. Ecancermedicalscience 2014; 8: 435.

[33] Shinohara K, Connolly JA, Presti JC, Jr., Carroll PR. Cryosurgical treatment of localized prostate cancer (stages $\mathrm{T} 1$ to $\mathrm{T} 4$ ): preliminary results. J Urol 1996; 156: 115-120; discussion 120-111.

[34] Bahn DK, Lee F, Solomon MH, Gontina H, Klionsky DL, Lee FT, Jr. Prostate cancer: US-guided percutaneous cryoablation. Work in progress. Radiology 1995; 194: 551-556.

[35] Cohen JK, Miller RJ, Rooker GM, Shuman BA. Cryosurgical ablation of the prostate: two-year prostate-specific antigen and biopsy results. Urology 1996; 47: 395-401.

[36] Chin JL, Al-Zahrani AA, Autran-Gomez AM, Williams AK, Bauman G. Extended followup oncologic outcome of randomized trial between cryoablation and external beam therapy for locally advanced prostate cancer (T2c-T3b). J Urol 2012; 188: 1170-1175.

[37] Jones JS, Rewcastle JC, Donnelly BJ, Lugnani FM, Pisters LL, Katz AE. Whole gland primary prostate cryoablation: initial results from the cryo on-line data registry. $J$ Urol 2008; 180: 554-558.

[38] Guo Z, Si T, Yang X, Xu Y. Oncological outcomes of cryosurgery as primary treatment in $\mathrm{T} 3$ prostate cancer: experience of a single centre. BJU Int 2015; 116: 79-84.

[39] Long JP, Fallick ML, LaRock DR, Rand W. Preliminary outcomes following cryosurgical ablation of the prostate in patients with clinically localized prostate carcinoma. J Urol 1998; 159: 477-484.
[40] Robinson JW, Donnelly BJ, Siever JE, Saliken JC, Ernst SD, Rewcastle JC, et al. A randomized trial of external beam radiotherapy versus cryoablation in patients with localized prostate cancer: quality of life outcomes. Cancer 2009; 115: 4695-4704.

[41] Bales GT, Williams MJ, Sinner M, Thisted RA, Chodak GW. Shortterm outcomes after cryosurgical ablation of the prostate in men with recurrent prostate carcinoma following radiation therapy. Urology 1995; 46: 676-680.

[42] Izzo F. Other thermal ablation techniques: microwave and interstitial laser ablation of liver tumors. Ann Surg Oncol 2003; 10: 491-497.

[43] Tranberg KG. Percutaneous ablation of liver tumours. Best Pract Res Clin Gastroenterol 2004; 18: 125-145.

[44] Veenendaal LM, de Jager A, Stapper G, Borel Rinkes IH, van Hillegersberg R. Multiple fiber laser-induced thermotherapy for ablation of large intrahepatic tumors. Photomed Laser Surg 2006; 24 3-9.

[45] Germer CT, Roggan A, Ritz JP, Isbert C, Albrecht D, Muller G, et al. Optical properties of native and coagulated human liver tissue and liver metastases in the near infrared range. Lasers Surg Med 1998; 23: 194-203.

[46] Whelan WM, Wyman DR, Wilson BC. Investigations of large vessel cooling during interstitial laser heating. Med Phys 1995; 22: 105-115.

[47] Solon LR, Aronson R, Gould G. Physiological implications of laser beams. Science 1961; 134: 1506-1508.

[48] Muschter R, Hofstetter A. Interstitial laser therapy outcomes in benign prostatic hyperplasia. J Endourol 1995; 9: 129-135.

[49] Bown SG. Phototherapy in tumors. World J Surg 1983; 7: 700-709.

[50] Lindner U, Weersink RA, Haider MA, Gertner MR, Davidson SR, Atri M, et al. Image guided photothermal focal therapy for localized prostate cancer: phase I trial. J Urol 2009; 182: 1371-1377.

[51] Lindner U, Lawrentschuk N, Weersink RA, Davidson SR, Raz O, Hlasny E, et al. Focal laser ablation for prostate cancer followed by radical prostatectomy: validation of focal therapy and imaging accuracy. Eur Urol 2010; 57: 1111-1114.

[52] Oto A, Sethi I, Karczmar G, McNichols R, Ivancevic MK, Stadler WM, et al. MR imaging-guided focal laser ablation for prostate cancer: phase I trial. Radiology 2013; 267: 932-940.

[53] Natarajan S, Raman S, Priester AM, Garritano J, Margolis DJ, Lieu P, et al. Focal laser ablation of prostate cancer: Phase I clinical trial. $J$ Urol 2016; 196: 68-75.

[54] Eggener SE, Yousuf A, Watson S, Wang S, Oto A. Phase II Evaluation of magnetic resonance imaging guided focal laser ablation of prostate cancer. J Urol 2016; 196: 1670-1675.

[55] Natarajan S, Jones TA, Priester AM, Geoghegan R, Lieu P, Delfin M, et al. Focal laser ablation of prostate cancer: feasibility of magnetic resonance imaging-ultrasound fusion for guidance. J Urol 2017; 198 : 839-847.

[56] Schulman CC, Zlotta AR. Transurethral needle ablation of the prostate (TUNA): pathological, radiological and clinical study of a new office procedure for treatment of benign prostatic hyperplasia using low-level radiofrequency energy. Semin Urol 1994; 12: 205-210.

[57] Strohmaier WL, Bichler KH, Bocking A, Fluchter SH. Histological effects of local microwave hyperthermia in prostatic cancer. Int $J$ Hyperthermia 1991; 7: 27-33.

[58] Van Cauwelaert RR, Castillo OC, Aquirre CA, Azocar GH, Medina FI. Transurethral microwave thermotherapy for the treatment of benign prostatic hyperplasia: preliminary experience. Eur Urol 1993; 23: 282-284.

[59] Djavan B, Zlotta AR, Susani M, Heinz G, Shariat S, Silverman $\mathrm{DE}$, et al. Transperineal radiofrequency interstitial tumor ablation of the prostate: correlation of magnetic resonance imaging with histopathologic examination. Urology 1997; 50: 986-992; discussion 
992-983.

[60] Zlotta AR, Djavan B, Matos C, Noel JC, Peny MO, Silverman DE, et al. Percutaneous transperineal radiofrequency ablation of prostate tumour: safety, feasibility and pathological effects on human prostate cancer. Br J Urol 1998; 81: 265-275.

[61] Wu KJ, Qi DF, Li X. Transperineum RF multi-hook probe interstitial ablation for treatment of begin prostatic hyperplasia (BPH) and prostatic cancer (PC). China Journal of Modern Medicine 2002; 12: 4.

[62] Hu ZQ, Ma YZ, Ye Z, Du GH, Guo XL, Song XD, et al. Mutipolar rasiofrequency thermal ablation for the treatment of prostate carcinoma (Report 5 cases). Journal of Clinical Urology 2003; 18: 276-277.

[63] Shariat SF, Raptidis G, Masatoschi M, Bergamaschi F, Slawin KM. Pilot study of radiofrequency interstitial tumor ablation (RITA) for the treatment of radio-recurrent prostate cancer. Prostate 2005; 65: 260-267.

[64] Ma BJ, Xu Y, Niu YJ, Chang JW, Zhang SM, Ma TX. Transrectal ultrasound (TRUS) guided transperineal radiofrequency ablation of prostate carcinoma. Xiandai Miniao Waike Zazhi 2006; 11: 32-34.

[65] Zhang L, Wang LG, Fan WJ, Ouyang YS. CT-guided percutaneous multipolar rasiofrequency ablaiton for carcinoma of prostate. Guangzhou Medicine 2009; 40: 11-13.

[66] Xu EJ, li K, Zheng RQ, Su ZZ, Si TJ, Sun QP,et al. The preliminary study of radiofrequency ablation in combination with hormonal therapy for the treatment of intermediate and advanced prostate cancer. Chin J Endourology (Electronic Edition) 2012; 6: 53-54.

[67] Liu R, Duan S, Cao H, Cao G, Chang Z, Zhang Y, et al. A pilot study of the shapes of ablation lesions in the canine prostate by laser, radiofrequency and microwave and their clinical significance. PLoS One 2020; 15(4): e0223229.

[68] Ouzzane A, Betrouni N, Valerio M, Rastinehad A, Colin P, Ploussard G. Focal therapy as primary treatment for localized prostate cancer: definition, needs and future. Future Oncol 2017; 13: 727-741.

[69] Ahmed HU. The index lesion and the origin of prostate cancer. $N$ Engl J Med 2009; 361: 1704-1706.

[70] Karavitakis M, Winkler M, Abel P, Livni N, Beckley I, Ahmed HU. Histological characteristics of the index lesion in whole-mount radical prostatectomy specimens: implications for focal therapy. Prostate Cancer Prostatic Dis 2011; 14: 46-52.

[71] Radtke JP, Schwab C, Wolf MB, Freitag MT, Alt CD, Kesch C, et al. Multiparametric magnetic resonance imaging (MRI) and MRItransrectal ultrasound fusion biopsy for index tumor detection: Correlation with radical prostatectomy specimen. Eur Urol 2016; 70: 846-853.

[72] Valerio M, Shah TT, Shah P, McCartan N, Emberton M, Arya M, et al. Magnetic resonance imaging-transrectal ultrasound fusion focal cryotherapy of the prostate: A prospective development study. Urol Oncol 2017; 35: 150 e151-150 e157. 